\title{
Effects of iron-based fuel borne catalyst addition on microstructure, element composition and oxidation activity of diesel exhaust particles
}

Junheng Liu ${ }^{a *}$, Lejian Wanga ${ }^{\mathrm{a}}$, Ping Sun ${ }^{\mathrm{a}}$, Pan Wang ${ }^{\mathrm{a}}$, Yuqiang Li ${ }^{\mathrm{b}}$, Hongjie $\mathrm{Ma}^{\mathrm{c}}$, Pengcheng $\mathrm{Wu}^{\mathrm{a}}$, Zengguang Liu ${ }^{\mathrm{a}}$

${ }^{a}$ School of Automotive and Traffic Engineering, Jiangsu University, Zhenjiang 212013, China

${ }^{\mathrm{b}}$ School of Energy Science and Engineering, Central South University, Changsha 410083, China

${ }^{\mathrm{c}}$ Institute of Industrial Research, University of Portsmouth, Portsmouth, Hampshire PO1 2EG, United Kingdom

*Corresponding author: Junheng Liu

Tel: +86-511-8879 7620

Fax: +86-511-8879 7620

Email address: liujunheng365@163.com 
Abstract: Metal-based fuel borne catalysts (FBC) have been extensively studied as an effective technology to reduce diesel particles and assist diesel particulate filter (DPF) regeneration. In this study, FBC fuels were prepared with Fe element mass fractions of 0, 100, 200, 300 and $400 \mathrm{mg} / \mathrm{kg}$ (marked as Diesel, Fe100, Fe200, Fe300 and Fe400). The effects of FBC additions on fuel economy and emission characteristics were carried out on a common-rail engine. Also, particle size distribution, microstructure, surface functional groups, element content and oxidation properties of exhaust particles were systematically analyzed. Results showed that the brake thermal efficiency was improved with the addition of FBC in diesel fuel, especially at low load, and the NOx and smoke emissions showed a decreasing trend. Compared with Diesel particles, the total mass concentration and the mean particle diameter of Fe300 particles decreased, the overall particle size distribution moved from coarse mode to accumulation mode, however, the total number concentration increased. Fe300 particles had larger layer spacing and microcrystalline curvature, smaller microcrystalline size and lower graphitization. In addition, the relative contents of $\mathrm{OH}$ and aliphatic $\mathrm{C}-\mathrm{H}$ in $\mathrm{Fe} 300$ particles were higher than those in Diesel particles. The relative content of $\mathrm{C}$ atoms in Fe300 particles decreased, while the relative content of $\mathrm{O}$ atoms increased. Temperature-programmed-oxidation experiments indicated that semi-volatile organic components appeared in Fe300 particles, the peak temperature of weight loss rate decreased by $131^{\circ} \mathrm{C}$ as compared with Diesel particles, the activation energy was also significantly lower, and therefore the particle oxidation activity was improved.

Key words: common-rail engine; iron-based fuel borne catalyst; soot oxidation; particle size distribution; element composition; particulate matter 


\section{Introduction}

In order to deal with the increasingly severe environmental problems and the crisis of energy shortage, the conventional diesel engine needs to make improvements in reducing emissions and improving thermal efficiency. In recent years, how to break the soot-NOx trade-off relationship has become a research hotspot. Some advanced combustion concepts, such as premixed low-temperature combustion (LTC), indicate that the exhaust gas recirculation (EGR) can simultaneously reduce NOx and soot emissions [1,2]. In addition, the more common approach is to use EGR technology to suppress the generation of NOx in the cylinder [3,4], and coupled with diesel particulate filter (DPF) to reduce the particulate matter emission [5]. However, with the deposition of particles in DPF, the back pressure of diesel engine will increase, which will worsen the performance of engine and increase the fuel consumption $[6,7]$. Therefore, DPF regeneration is directly related to its capture efficiency and the performance of diesel engine $[8,9]$. There are two ways of DPF regeneration: namely active regeneration and passive regeneration. Active regeneration is to increase the exhaust temperature through additional heating device or post fuel injection to reach the oxidation temperature of soot. Passive regeneration is achieved by reducing the ignition temperature of diesel soot particles with the help of catalysts [10].

Adding appropriate fuel borne catalyst to diesel fuel can change its physicochemical properties, effectively reduce the oxidation temperature of soot, and thus improve the passive regeneration ability of DPF [11]. Metal additives (such as silver, iron, cerium oxide, aluminum oxide, manganese oxide, copper oxide and platinum, etc.) are often used as fuel borne catalysts to realize the passive regeneration of DPF and reduce particulate matter emissions [12-17]. Because nanoscale metal can catalyze fuel combustion and participate in the formation and oxidation of soot in the cylinder, the contact between soot and nanoscale metal oxide catalyst is closer. Moreover, adding nanoparticles to fuel increases the surface area to volume ratio of the particles significantly, allowing oxidants to come into contact with more fuel to promote 
combustion.

In order to study the effect of nano particles on the physical and chemical properties of diesel fuel, Gumus et al. [15] prepared test fuels by adding alumina oxide and copper oxide nanoparticles to diesel fuel, and compared with the physical and chemical properties of neat diesel fuel. The results showed that adding ppm level nanoparticles to diesel had little effect on kinematic viscosity, sulfur, cold filter plug point, density and distillation characteristics of diesel, but the flash point temperature and cetane index increased slightly. In addition, they found that the PH value, type and concentration of dispersants had a great influence on the dispersion of nanoparticles in diesel fuel. In terms of emissions, the emissions of $\mathrm{CO}, \mathrm{HC}$ and NOx were significantly reduced by adding $\mathrm{Al}_{2} \mathrm{O}_{3}$ to neat diesel fuel, which were $11 \%, 13 \%$ and $6 \%$ respectively. However, the research results of Celik et al. [18] showed that the viscosity, density and flash point of the fuel decreased and the calorific value increased after adding organic manganese additive to rapeseed methyl ester. Compared with rapeseed methyl ester fuel, the highest thermal efficiency increased by $6.23 \%$ after adding organic manganese additive. However, the brake specific fuel consumption decreased by $6.87 \%$.

Several studies have investigated the effects of metal catalytic on particulate matter formation, oxidation and mass emissions and have explored catalyst on engine performance and emissions. Lenin et al. [14] studied the effects of manganese oxide and copper oxide nano oxide additives on diesel engine emissions. The results showed that manganese had a strong inhibitory effect on diesel exhaust emissions, and CO and NOx reduced by $37 \%$ and $4 \%$ respectively. Najafi et al. [16] studied the effect of silver nanoparticles on the combustion parameters of diesel engine. The experimental results showed that the peak pressure and the rise rate of pressure in cylinder were significantly higher than that of pure diesel fuel after adding nano additives into the diesel biodiesel blend because of the shorter ignition delay. Moreover, the combustion duration was shorter and the maximum pressure in cylinder was higher. Javed et al. [19] studied the effects of high ambient temperature and different concentrations of nanoparticles on the autoignition and combustion 
characteristics of heptane-based nanofluid droplet. The results showed that the ignition delay time of pure heptane droplets and the $\mathrm{n}-\mathrm{Al} / \mathrm{heptane}$ droplets decreased exponentially with the increase of ambient temperature. In addition, at a higher temperature $\left(750 \sim 850^{\circ} \mathrm{C}\right)$, the gasification rate of nanofluid droplets was significantly faster than that of pure heptane droplets. The research results of Sajeevan et al. [20] showed that the improvement of brake thermal efficiency was proportional to the concentration of cerium zirconium mixed oxide nanoparticles in diesel, but an average of 31\% reduction in smoke was observed for sample with concentration of $17.5 \mathrm{ppm}$. They attributed this to the reason that the cerium oxide acting as an oxygen buffer, allowed the fuel to burn completely for a long time, thus improving efficiency and reducing smoke emissions [21]. In Keskin et al. [22] study, they produced metallic-based additives by synthesizing of resin acid (abietic acid) with $\mathrm{MnO}_{2}$ or $\mathrm{MgO}$. Maximum reduction of specific fuel consumption was recorded as $4.16 \%$, and power and torque values of engine increased slightly by Mn-based additive. In addition, CO and smoke opacity was reduced by $16.35 \%$ and $29.82 \%$ respectively, but the NOx emissions increased.

Recently, the mechanism of reducing smoke emission by fuel additives has been studied. Some studies have shown that $\mathrm{CeO}_{2}$ effectively provides lattice oxygen to soot, creating oxygen vacancies that are quickly filled with gaseous oxygen and thus promote soot oxidation [23,24]. However, some researchers think the reason of emission reduction is that the metals function either by reacting with water to produce hydroxyl radicals, which enhance soot oxidation, or by direct reaction with the carbon atoms in the soot, thereby lowering the oxidation temperature [25].

In the process of experimental research, due to the limitation of hardware, it is difficult to carry out real-time analysis on the detailed combustion process and intermediate products, but the numerical analysis makes up for this disadvantage. Raj et al. [26] studied the reduction effect of iron pentacarbonyl as fuel additive on NO and soot precursors in methane/air diffused flames through numerical analysis. The results showed that with the increase of $\mathrm{Fe}(\mathrm{CO})_{5}$ concentration, the content of $\mathrm{C}_{2} \mathrm{H}_{\mathrm{x}}$, the commonly accepted 
precursor of soot and NO species decreased in proportion. They believed that the reduction of emission of iron related species is due to the scavenging of the reaction propagating radicals by the formation of iron, iron oxide and iron hydroxide species in the flame. Mehregan et al. [27] studied the combustion characteristics and pollutant emissions of ethanol and n-decane liquid fuels with the addition of aluminum nanoparticles by numerically research. The results showed that aluminum nanoparticles reduced the flame temperature. In addition, the presence of aluminum nanoparticles in decane and ethanol fuels helped to reduce $\mathrm{CO}$ and $\mathrm{NOx}$ emissions, which confirmed that the addition of nanoparticles improved combustion characteristics.

Iron-based fuel additives have optimistic application prospects because of their soluble in diesel fuels, heat stable, inexpensive, and easy to handle [28]. Recent studies suggested that particle mass, total particle volume, and black carbon emissions were reduced by $30 \sim 40 \%$ during soot oxidation due to iron-based additives, but particle number concentrations were increased by about five times [29]. Ma et al. [30] investigated the effect of an Fe-based homogeneous combustion catalyst on the emission characteristics. The results showed that in addition to the benefit of improved fuel efficiency, the homogeneous combustion catalyst significantly reduced the emissions of particulate matter, $\mathrm{CO}$ and unburnt hydrocarbon (UHC) from diesel engines. Although Fe-based fuel borne catalyst have great potential to reduce particulate matter, Unregulated emissions due to the addition of $\mathrm{Fe}$ are more harmful to the environment and health. Several results showed that particle-phase polycyclic aromatic hydrocarbons (PAHs) and n-alkanes emissions increased with the increase of Fe element in the fuels, and the proportion of both organic carbon (OC) and water-soluble organic carbon (WSOC) in particles increased simultaneously. Benzene and n-undecane emissions increased and toluene emission decreased, while other volatile organic compounds (VOC) emissions had basically no change [31,32]. The effects of ferrocene on flame temperature and soot properties were also studied. The iron from ferrocene reacted with $\mathrm{O}$ and $\mathrm{OH}$ radicals, which dropped the 
flame temperature and restrained smaller PAHs from growing into bigger ones [33]. The above-mentioned studies of the influences of Fe on fuel efficiency, NOx, soot particles, PAHs and flame were performed separately. Some studies show that the structural characteristics of soot particles determine their physical and chemical properties, for instance, the degree of graphitization of particles had a significant effect on the number and location of active sites on the carbon surface [34]. Wang et al. [35] reported that the concentrations of aliphatic $\mathrm{C}-\mathrm{H}, \mathrm{C}=\mathrm{O}$ and $\mathrm{C}-\mathrm{OH}$ groups from the soot surface were dependent on the combustion phases, and aliphatic $\mathrm{C}-\mathrm{H}$ group is the main factor affecting the oxidation activity of soot particles. However, there are few systematic analyses of the surface functional groups, element content, microstructure and oxidation characteristics of diesel exhaust particles with the addition of iron-based fuel borne catalyst (Fe-FBC) into diesel fuel.

This study mainly investigated the influence of Fe-FBC on the performance of diesel engine and the physicochemical properties of exhaust particles. Firstly, the brake specific fuel consumption (BSFC), brake thermal efficiency (BTE), NOx and smoke emissions characteristics of Fe-FBC fuel with different proportions were studied on the engine bench, and the optimum Fe-FBC blending ratio was obtained. Secondly, the mass concentration and number concentration distributions and microstructure characteristics of Diesel and Fe-FBC particles were compared and analyzed. Thirdly, the surface functional groups and element content were investigated between Diesel and Fe-FBC particles. Finally, the oxidation characteristics of Diesel and Fe-FBC particles were studied by thermogravimetric analysis (TGA) and Coast-Redfern integral method.

\section{Experimental setup and methods}

\subsection{Test engine and apparatus}

The experiments were conducted on a 4-cylinder, turbocharged, intercooled, high-pressure common-rail diesel engine with the displacement of 4.32L and compression ratio of 17.5. The main parameters of engine 
are listed in Table 1, and the schematic layout of the diesel engine test system is shown in Fig. 1. In the experiment, the engine speed and torque were controlled by an electrical dynamometer (AVL 504/4.6 SL), which adjusts the torque output and keeps the speed constant automatically. The instantaneous fuel consumption monitor (AVL 735S) was used to measure the fuel consumption rate. The filter-type smoke meter (AVL 415S) was used to measure the smoke emission, and the gaseous emission analyzer (Horiba MEXA 7200D) was used to measure the NOx emission of the engine, where NOx was detected using a chemiluminescent detector (CLD) analyzer. The gas analyzers were calibrated with zero gas and standard gas before the experiment [36]. Calibrated sensors/probes were installed to monitor and control the ambient and intake air temperatures, cooling water temperature, oil temperature and the exhaust temperature. The intake air temperature and the cooling water temperature were controlled in closed-loop at $40{ }^{\circ} \mathrm{C}$ and $80{ }^{\circ} \mathrm{C}$, respectively, to eliminate their effects on engine performance.

Table 1 Specifications of the test engine.

\begin{tabular}{ll}
\hline Item & Specification \\
\hline Engine type & 4-cylinder, in-line, turbocharged, intercooling \\
Fuel injection system & Common-rail \\
Combustion chamber shape & Direct injection $\omega$ type \\
Bore $\times$ stroke $(\mathrm{mm})$ & $108 \times 118$ \\
Compression ratio & 17.5 \\
Displacement $(\mathrm{L})$ & 4.32 \\
Rated power $(\mathrm{kW} / \mathrm{r} / \mathrm{min})$ & $95 / 2600$ \\
Maximum torque $(\mathrm{Nm} / \mathrm{r} / \mathrm{min})$ & $400 / 1500$ \\
Injection pressure $(\mathrm{MPa})$ & 130 \\
Valve overlap angle $\left({ }^{\circ} \mathrm{CA}\right)$ & 99 \\
\hline
\end{tabular}




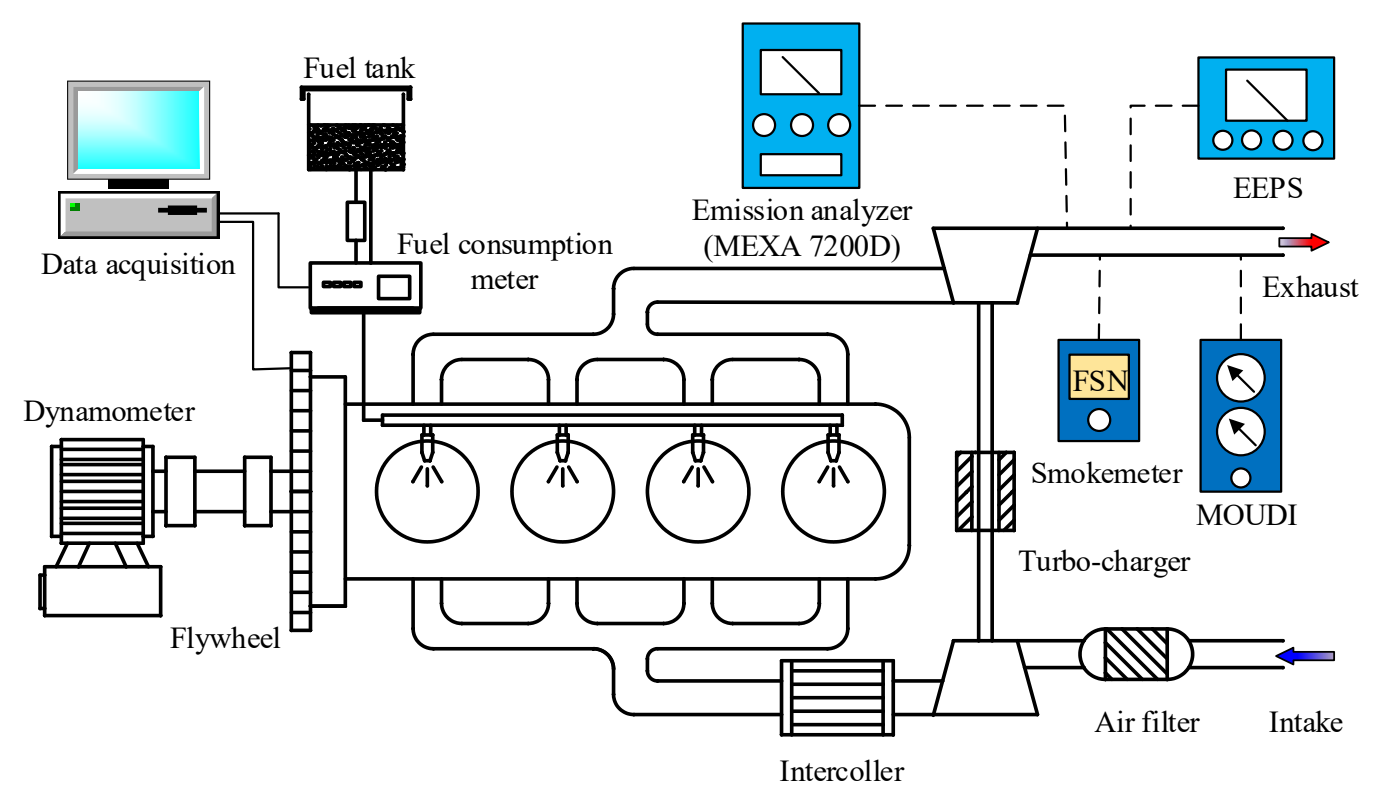

Fig. 1. Schematic of the experimental system.

\subsection{Iron-based fuel preparation}

Usually, fuel borne catalysts (FBC) are mainly divided into two categories: one is powder organic metals, such as aluminum oxide, copper oxide, cerium dioxide etc. The other is solvent organic metal solutions $[11,12,14,16,18,24,25,37]$. The difference between them lies in the contact degree when they are mixed with diesel fuel. In order to obtain good dispersion in fuel, powder additives need to be realized by combining physical and chemical dispersion. However, solvent FBC can be directly added to the fuel, and its organic solvent can be well mixed with the fuel without stratification. In the present study, F7994 (iso-dodecane as the solvent, and 4\% iron as the solute) produced by Infirium Corporation was select as the solvent FBC, and it can be mixed with diesel fuel at any proportion. The commercial Euro V diesel was used as the reference fuel for the fuel blending, and its sulfur content is less than $10 \mathrm{ppm}$. The blended fuels with Fe content of 0 $\mathrm{mg} / \mathrm{kg}, 100 \mathrm{mg} / \mathrm{kg}, 200 \mathrm{mg} / \mathrm{kg}, 300 \mathrm{mg} / \mathrm{kg}$ and $400 \mathrm{mg} / \mathrm{kg}$ were prepared with the $\mathrm{F} 7994$ solution as the additive. They were marked as Diesel, Fe100, Fe200, Fe300 and Fe400, respectively. The blended fuels were maintained statically for six months without obvious stratification and turbidity, which indicated that the blended fuel had good stability. 


\subsection{Experimental method and procedure}

The experiments were carried out under the rated speed of $2600 \mathrm{r} / \mathrm{min}$, and the brake mean effective pressure (BMEP) of $0.269 \mathrm{MPa}, 0.537 \mathrm{MPa}, 0.806 \mathrm{MPa}$ and $1.074 \mathrm{MPa}$ were selected as the testing conditions, and their corresponding engine loads were $25 \%, 50 \%, 75 \%$ and $100 \%$, respectively. The diesel engine burned with Diesel, Fe100, Fe200, Fe300 and Fe400 successively. Each test was conducted with the same control strategy, so as to investigate the effects of Fe-FBC on brake specific fuel consumption (BSFC), brake thermal efficiency (BTE), NOx and smoke emissions.

In the rated power of engine burning Diesel and Fe300, the Micro-Orifice Uniform Deposit Impactor (MOUDI, Model 110R, USA MSP) was adopted to measure the particle mass concentration. The sampling volume flow was set at $30 \mathrm{~L} / \mathrm{min}$ and the sampling time was set at $30 \mathrm{~min}$. The particle number concentration was measured by the Engine Exhaust Particle Sizer (EEPS, Model 3090, USA TSI). The monitoring range was 5.6 560nm, and the sampling dilution ratio was set as 120:1, and the sampling temperature was $120^{\circ} \mathrm{C}$. The samples were continuously sampled for $5 \mathrm{~min}$ and averaged for analysis.

The microstructure of Diesel and Fe300 particles was analyzed by High Resolution Transmission Electron Microscope (HRTEM, JEM-2100, JEOL). The maximum magnification of electron microscope was 2.3 million, the point resolution was up to $0.24 \mathrm{~nm}$, and the lattice resolution was up to $0.14 \mathrm{~nm}$. The specific test methods are as follows: (1) dissolving the particle sample in ethanol solution to remove soluble organic fraction; (2) drying the particle sample, adjusting the magnification until the stacking of particles and the structure of single carbon microcrystalline can be clearly observed in the image, observing the microstructure of carbon particles; (3) using Digital Micrograph software to measure and analyze the layer spacing, microcrystalline size and microcrystalline curvature of the carbon particles. The image processing software Digital Micrograph was used to analyze particle microstructure parameters in great detail. During processing, the selected electron micrograph of the particles is shown in the form of a skeletonized binary 
image, and it accurately reflects the microstructural organization within the carbon layer. Statistical results for each structural parameter, extracted from the binary images, are displayed in the form of histograms and quantitatively distinguish the different particle microstructures [38]. The internal structure parameters of the particles are obtained from the electron microscope image samples of about 30 basic carbon particles under the same conditions.

The surface functional groups of particles were analyzed with the Fourier transform infrared spectrometer (FTIR, 670-IR+610-IR, USA Varian). The spectral range of the equipment was $4000 \mathrm{~cm}^{-1} \sim 400$ $\mathrm{cm}^{-1}$, the resolution was $0.1 \mathrm{~cm}^{-1}$, the transmittance accuracy was better than $0.1 \mathrm{~T} \%$, and the fast scanning speed was greater than 90 spectra/s. The specific test methods are as follows: (1) weighing $1 \mathrm{mg}$ Fe300 particles and 100mg dry potassium bromide powder respectively, grinding them evenly and pressing into tablets and Diesel particles are treated in the same way; (2) processing the infrared spectrum to get the parameters such as the position and intensity of the characteristic peaks; (3) using the corresponding infrared characteristic peaks of each molecular group in the standard infrared spectrum database to determine the ownership of the absorption band, the molecular structure and the existing functional groups.

After the diesel engine burned Fe-FBC fuel, there will be more Fe element in the exhaust particles. Fe element has a lively nature, which can change the content of elements in the particles and the proportion of chemical components in the particles. The X-ray photoelectron spectroscopy (XPS, ESCALAB250 Xi, USA Thermo Fisher) was used to analyze the surface element content of Diesel and Fe300 particles. The ultimate energy resolution of the instrument was $0.43 \mathrm{eV}$, and the energy analysis range was $0 \mathrm{eV} \sim 5000 \mathrm{eV}$. After the completion of XPS scanning, XPS peak software was used to divide the peaks of the scanned XPS map, so as to obtain the components corresponding to the elements. The higher the coincidence between the envelope formed by fitting several peaks in each narrow spectrum and the original spectrum, the higher the reliability of peak separation. 
Thermal gravimetric analysis is an important method to explore the oxidation characteristics of particles $[39,40]$. The oxidation characteristics of particles were analyzed by conducting temperature-programmed-oxidation experiments and exploring the relationship between its mass and temperature. In this study, the simultaneous thermal analyzer (TGA/DSC, Switzerland Mettler) was used to analyze Diesel and Fe300 particles. The programmed temperature range was $40 \sim 800{ }^{\circ} \mathrm{C}$, the heating rate was set at $10{ }^{\circ} \mathrm{C} / \mathrm{min}$, the protective gas was pure nitrogen, and the reaction gas was a mixture of nitrogen and oxygen according to 4:1. It simulated the exhaust environment of diesel engine, and the flow rate of protective gas and reaction gas was $50 \mathrm{ml} / \mathrm{min}$. Thermogravimetric and derivative thermogravimetric curves (TG/DTG) of particle samples were obtained by thermogravimetry experiments, and the activation energy of particle samples was calculated by Coats-Redfern integral method (see details in refs $[37,41]$ ), as shown below:

$$
\ln \left[\frac{-\ln (1-\alpha)}{T^{2}}\right]=\ln \frac{A R}{\beta E}-\frac{E}{R T}
$$

Where $\alpha$ denotes the relative weight loss rate of test fuels $(\%)$; T denotes the temperature $(\mathrm{K})$; A denotes the pre-exponential factor $(1 / \mathrm{min}) ; \beta$ is the heating $\operatorname{rate}(\mathrm{K} / \mathrm{min})$; $\mathrm{E}$ denotes activation energy $(\mathrm{kJ} / \mathrm{mol})$; $\mathrm{R}$ denotes the gas constant. The steady state tests were repeated at least twice to ensure that the results are repeatable within the permissible errors. The experimental uncertainties and measuring accuracies of the main instruments are shown in Table 2.

Table 2 Accuracy and uncertainty of measured parameters.

\begin{tabular}{lllll}
\hline Instrument & Measured parameters & Range & Accuracy & Uncertainty (\%) \\
\hline Electric dynamometer & Speed & $0 \sim 5000 \mathrm{r} / \mathrm{min}$ & $0.05 \%$ & - \\
& Torque & $0 \sim 1000 \mathrm{Nm}$ & $0.1 \%$ & - \\
Fuel consumption meter & Fuel consumption & $0 \sim 50 \mathrm{~kg} / \mathrm{h}$ & $0.12 \%$ & 0.5 \\
Smoke meter & Smoke & $0 \sim 10 \mathrm{FSN}$ & $0.002 \mathrm{FSN}$ & 0.5 \\
Exhaust gas analyzer & NOx & $0 \sim 5000 \mathrm{ppm}$ & $2 \mathrm{ppm}$ & 1.8 \\
Thermal analyzer & Weight loss rate & $0 \sim 10 \mathrm{mg}$ & $0.1 \mu \mathrm{m}$ & 2.0 \\
\hline
\end{tabular}




\section{Results and discussion}

\subsection{Effects of Fe-FBC on engine performance}

The comparison diagram of BSFC and BTE of the test fuels under different loads at the speed of 2600 $\mathrm{r} / \mathrm{min}$ is shown in Fig. 2. Under different loads, with the increase of the blending ratio, the BSFC decreases obviously and the BTE increases. However, when Fe element content exceeds 300ppm, the improvement effect on the fuel economy of engine decreases. Compared with Diesel, the BSFC of Fe300 decreases by $12.2 \%$ and the BTE increases by $13.8 \%$ at $25 \%$ load. Nevertheless, at $100 \%$ load, BSFC decreases by $3.3 \%$ and BTE increases by $3.4 \%$. Maybe it's because Fe-FBC can effectively catalyze the oxidative combustion of fuel and promote the formation of more active radicals, thus accelerating the chain reaction rate, making the combustion advance and promoting the combustion more completely [42]. The improvement effect of Fe-FBC on fuel economy is not obvious at high load, which may be due to the combustion is relatively complete at high load and the catalytic effect is not obvious.
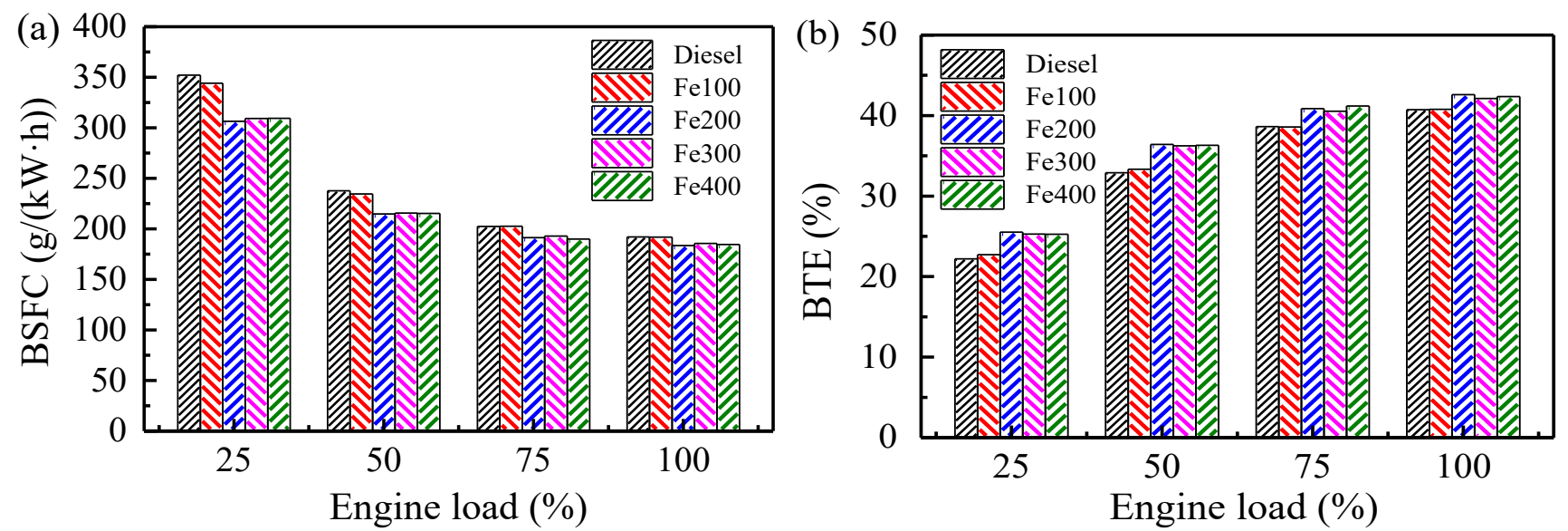

Fig. 2. Variation of BSFC (a) and BTE (b) as a function of engine load for the five fuels at the speed of $2600 \mathrm{r} / \mathrm{min}$.

The comparison of NOx and smoke emission of diesel engine burning four kinds of Fe-FBC and Diesel under different loads at $2600 \mathrm{r} / \mathrm{min}$ is shown in Fig. 3. The NOx emission decreases with the increase of Fe-FBC concentration, and Fe-FBC has the better improvement effect on NOx at high load. The NOx emission of Fe100, Fe200, Fe300 and Fe400 blending fuel decreases by $0.73 \%, 8.91 \%, 10.34 \%$ and $9.71 \%$ respectively at $100 \%$ load. This is because Fe-FBC can shorten the ignition delay period, reduce the amount 
of combustible mixture formed in the premixed combustion period, decrease the combustion temperature in the cylinder, and thus decrease NOx emissions. However, the excessive addition of iron-based additives in diesel fuel will increase the fuel reactivity in the cylinder, which make the catalytic combustion of Fe400 fuel in cylinder more intense, so the NOx emission of Fe400 is slightly higher than that of Fe300. Compared with the smoke emission of Diesel, the smoke emission of engine after burning Fe-FBC is significantly reduced, and the smoke suppression effect is the best under high load. The filter smoke number of Fe100, Fe200, Fe300 and Fe400 is reduced by $21.3 \%, 27.6 \%, 37.0 \%$ and $35.6 \%$, respectively, at 100\% load. The main reason is that the special crystal structure formed by the oxidation of Fe particles in the main combustion period can store oxygen, increase the number of $\mathrm{O}, \mathrm{H}, \mathrm{OH}$ and other active groups, which promotes the occurrence of chain reaction and makes the precursors of soot such as $\mathrm{C}_{2} \mathrm{H}_{2}$ and PHAs significantly reduced [43]. Moreover, Fe particles as catalytic center can effectively catalyze the oxidation of the soot which has been generated in the later combustion period, so as to reduce the smoke emission [44]. However, due to the existence of the oxidation products for iron-based additives, the excessive addition of Fe-FBC will increase the smoke emission, and therefore the smoke emission of Fe400 is slightly higher than that of $\mathrm{Fe} 300$.
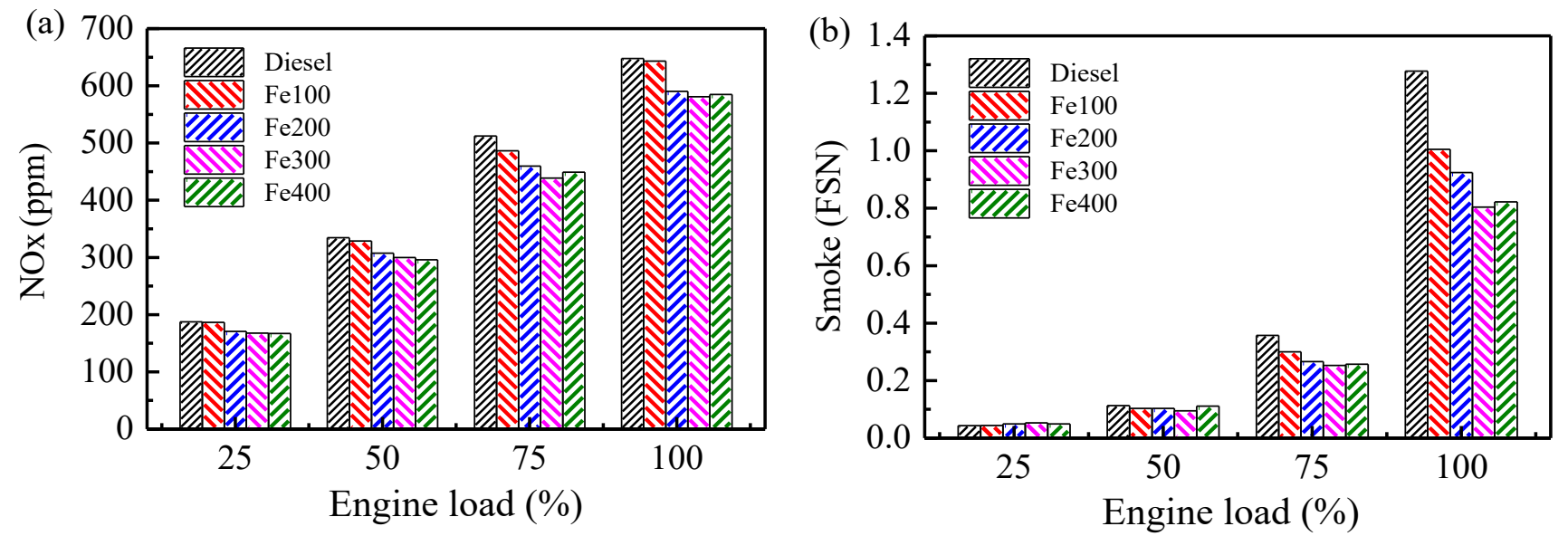

Fig. 3. Variation of NOx (a) and smoke (b) emissions as a function of engine load for the five fuels at the speed of $2600 \mathrm{r} / \mathrm{min}$.

Based on the effect of different Fe-FBC on the BSFC, BTE, NOx and smoke emission, it was found that 
there was a threshold value for Fe-FBC addition proportion, and the optimized addition proportion was 300ppm. Therefore, the following analysis of the physical and chemical characteristics of particulate matter was mainly based on the comparison between Fe300 and Diesel.

\subsection{Effects of Fe-FBC on particle size distribution}

Overall, some clear differences in particle mass concentration and number concentration between Fe300 and Diesel at full load of $2600 \mathrm{r} / \mathrm{min}$ are seen, as illustrated in Fig. 4. It is shown that the particle mass concentration of both Diesel and Fe300 appears a single peak lognormal distribution from Fig. 4(a). Compared with Diesel particles, the total mass concentration of Fe300 particles decreases by $20.58 \%$, but the proportion of particles in accumulated mode increases, and more than $90 \%$ of Fe 300 particles are concentrated in the accumulated mode. The particle size corresponding to $50 \%$ cumulative distribution of particles is defined as median diameter (Dp50). Fig. 4(b) shows that the mass median diameters of Diesel and Fe300 particles under the rated power are $0.426 \mu \mathrm{m}$ and $0.374 \mu \mathrm{m}$, respectively, and the mass median diameter of Fe300 particles decreases by $12.2 \%$. Fig. 4(c) shows that the particle number concentration of Diesel and Fe300 is in a logarithmic bimodal distribution, and the particle size range corresponding to the number concentration of Diesel particles is $9.3 \sim 4.3 \mathrm{~nm}$ and $60.4 \sim 80.6 \mathrm{~nm}$, respectively. The concentrations of $13.6 \%$ and $22.5 \%$ of the Diesel particles are concentrated in these two ranges. The bimodal peak value of Fe300 particle number concentration corresponds to the particle size range of $6.9 \sim 9.3 \mathrm{~nm}$ and $39.2 \sim 60.4 \mathrm{~nm}$ respectively, and $12.2 \%$ and $34.1 \%$ of the total particles are concentrated in these two ranges. Compared with Diesel particle, the total number concentration of Fe300 particle increases by $63.5 \%$. Fig. 4(d) shows that the number median diameter of Diesel and Fe300 is $50.8 \mathrm{~nm}$ and $39.2 \mathrm{~nm}$, respectively. The number median diameter of $\mathrm{Fe} 300$ particles decreases by $22.8 \%$. The number of Fe300 particles with large particle size decreases, and the particle size shifts to the small particle size. 

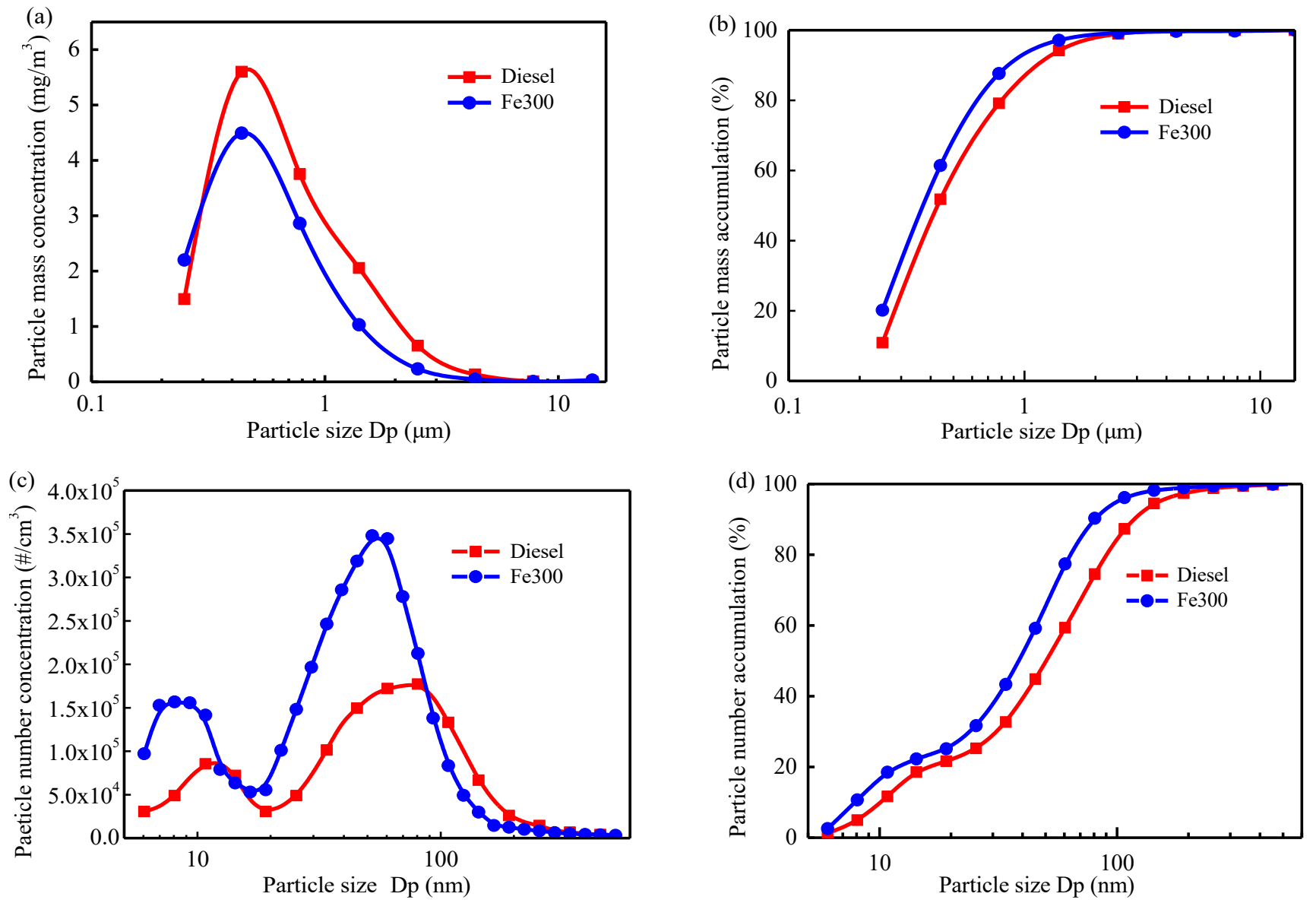

Fig. 4. Distributions of particle mass $(a, b)$ and number $(c, d)$ concentration from

Diesel and Fe300 under 100\% engine load of $2600 \mathrm{r} / \mathrm{min}$.

Fe-FBC mainly affects particle size through two aspects: on the one hand, the oxidation products of $\mathrm{Fe}$ particle in Fe-FBC, in the early stage of combustion, have special lattice structure, which can store oxygen, generate more $\mathrm{O}$ and $\mathrm{OH}$ active groups, reduce the high-temperature anoxic area, make fuel and air mix more completely, reduce the number of carbon smoke and collision probability. On the other hand, Fe particles in Fe-FBC agglomerate with soot particles in the process of combustion, which reduces the possibility of dehydrogenation and acetylene reaction of soot particles and suppresses the growth rate of soot particles. These aggregates containing Fe can process surface oxygen transport or oxygen diffusion during oxidation, so as to further decompose large particles and increase the number of nuclear mode particles $[45,46]$. 


\subsection{Microstructure analysis of soot particle}

In order to better observe the microstructural changes of soot after burning Fe300, the HRTEM was used to characterize the morphology and structural features, and the results are shown in Fig. 5. By analyzing the structure of soot, it can be found that soot is composed of the inner core formed by shorter microcrystals and the layered stacking outer periphery formed by long microcrystals. It can be observed from Fig. 5(a) that the stacking pattern of Diesel soot microcrystals is regular, and the carbon particles on the outer periphery of soot are closely arranged, which is different from that shown in Fig. 5(b). Fe lattice appears at the mark of Fe300 soot in Fig. 5(b), and the Fe lattice is embedded into the outer periphery of soot, which proves that Fe particles participate in the aggregation and coalescence of soot particles, and increases the disorder degree of carbon particles arrangement at the outer periphery of soot particles. The size of Fe lattice is about $10 \mathrm{~nm}$, which indicates that the existence of $\mathrm{Fe}$ lattice results in the peak value near $10 \mathrm{~nm}$ in the number concentration of particles.
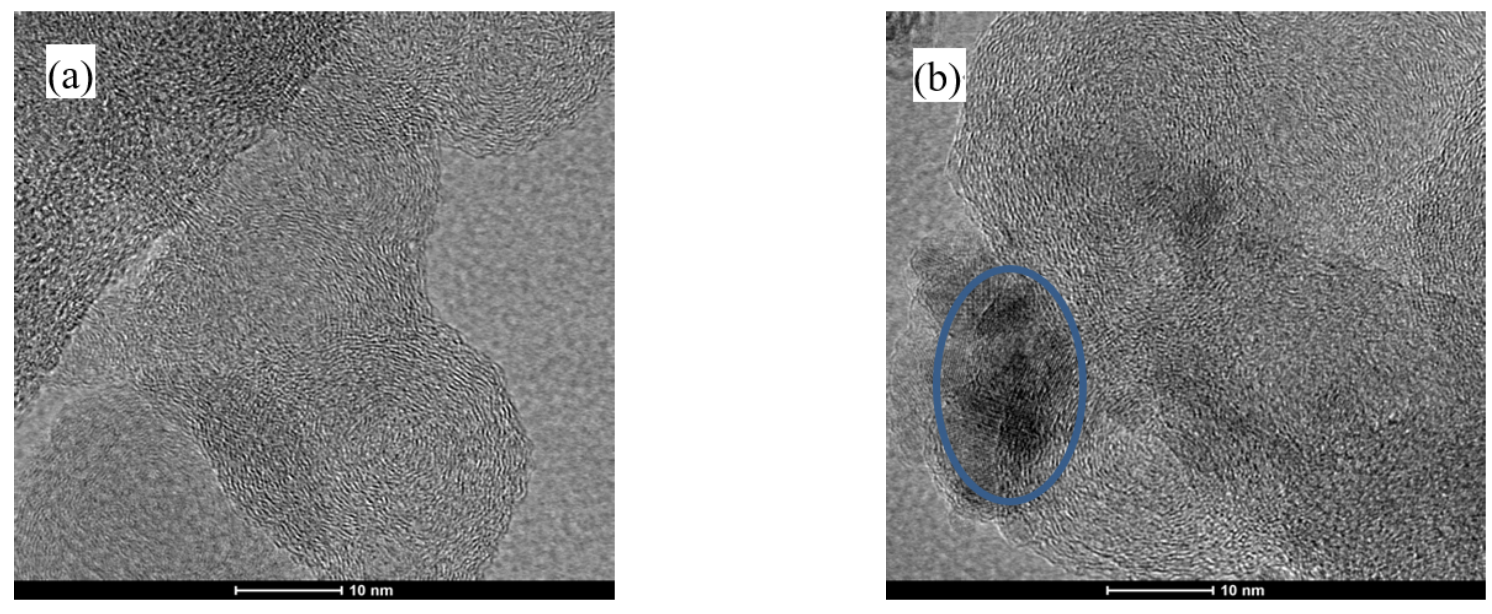

Fig. 5. Representative HRTEM images for different tested fuels: (a) Diesel; (b)Fe300.

The distribution regularities of the carbon particle layer spacing, microcrystalline size and microcrystalline curvature of diesel engine burning Diesel and Fe300 under rated power are shown in Fig. 6. It can be seen from Fig. 6(a) that the layer spacing of Diesel soot is relatively small, and the distribution of layer spacing moves to the direction of larger layer spacing after Fe-FBC is blending. The average distance between the microcrystalline layers of Diesel soot and Fe300 soot is $0.3447 \mathrm{~nm}$ and $0.3856 \mathrm{~nm}$ respectively, 
indicating that the internal structure of Fe300 soot is looser. Fig. 6(b) shows that the microcrystalline size of Fe300 soot tends to shift to the small size direction compared with Diesel, and the average microcrystalline size of Diesel and Fe300 soot is $2.196 \mathrm{~nm}$ and $2.039 \mathrm{~nm}$ respectively, which indicates that the continuity of microcrystalline stacking inside the soot is reduced. Fig. 6(c) shows that the peak value of microcrystalline curvature in Diesel soot is around 1.15, while that in Fe300 soot is around 1.25. The mean value of microcrystalline curvature is 1.18 and 1.24 respectively. The microcrystalline curvature of Fe 300 soot is larger than that of Diesel, indicating that the bending degree of microcrystal increases after burning Fe 300. This may be due to the fact that Fe particles, as the activation center, accelerate the oxidation of fuel and improve the reaction rate, thus suppressing the growth of carbon microcrystals, increasing the disorder degree of the structure of carbon particles and reducing the graphitization $[47,48]$.
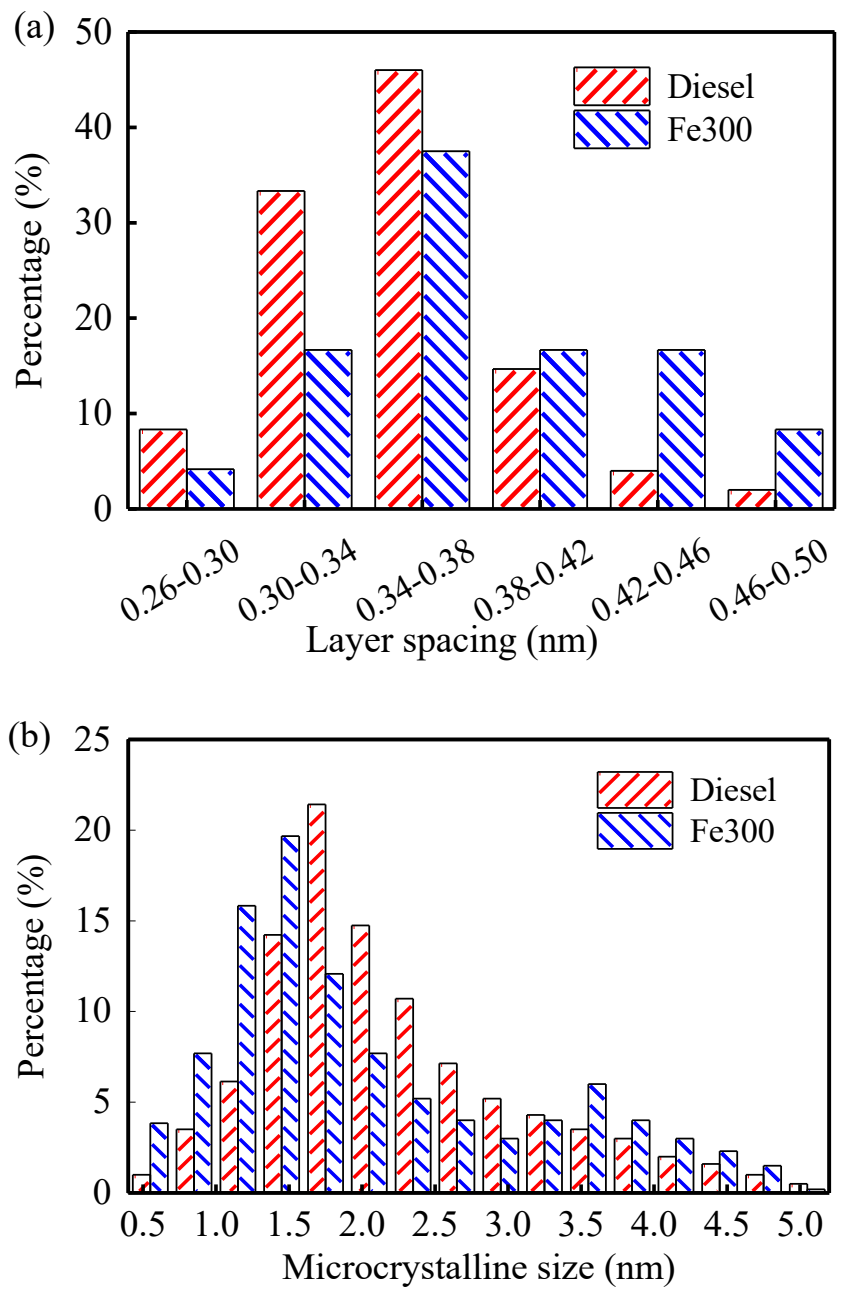


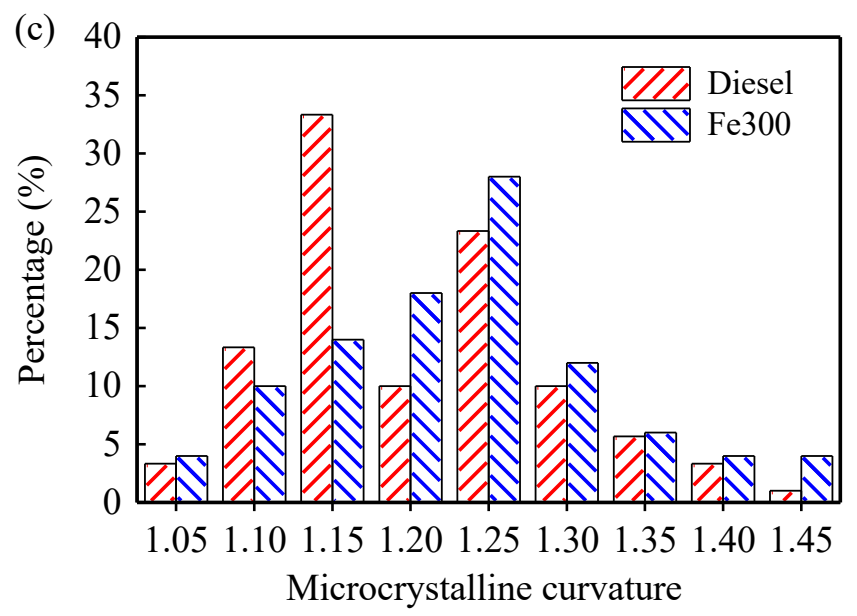

Fig. 6. Characteristic parameters of carbon particles of Diesel and Fe300:

(a) Layer spacing; (b) Microcrystalline size; (c) Microcrystalline curvature.

\subsection{Surface functional group analysis of soot particle}

The oxidation characteristics of soot particles are affected not only by the size of microcrystals, the distance between layers and the curvature of microcrystals, but also related to the type and quantity of functional groups at the edge of microcrystals. FTIR technique can give a deep insight into the types of functional groups at the edge of microcrystals. The FTIR spectra of the Diesel and Fe300 particle samples in the wave number range from $4000 \mathrm{~cm}^{-1}$ to $400 \mathrm{~cm}^{-1}$ are pictured in Fig. 7. By analyzing the peak positions of different infrared characteristic peaks in the FTIR spectrum, the types of functional groups on the surface of soot particles can be determined. The peak intensity in the spectrum is the comparison value based on $\mathrm{C}=\mathrm{C}$ bond peak intensity. After normalization, the peak height ratio of aliphatic $\mathrm{C}-\mathrm{H}$ and $\mathrm{C}=\mathrm{C}$ characteristic peak is obtained as $\mathrm{I}_{\mathrm{C}-\mathrm{H}} / \mathrm{I}_{\mathrm{C}=\mathrm{C}}$. The change of absorbance represents the change of relative concentration of hydrogen bond in the sample [49].

It can be seen from the FTIR spectrum that the wide absorption band with wave number around 3400 $\mathrm{cm}^{-1}$ belongs to $\mathrm{OH}$ stretching vibration, and the hydrogen bond absorption band of Fe300 particles is significantly stronger than Diesel, indicating that the concentration of hydrogen bond in the particles is significantly increased with the addition of Fe. The peak value of Diesel particles at the wave number of 
$2920 \mathrm{~cm}^{-1}$ is attributed to the antisymmetric stretching vibration of saturated hydrocarbon $\mathrm{CH}_{2}$, and the peak value of $2850 \mathrm{~cm}^{-1}$ is attributed to the symmetric stretching vibration of saturated hydrocarbon $\mathrm{CH}_{2}$. The peak value of $\mathrm{Fe} 300$ particles around $2923 \mathrm{~cm}^{-1}$ is attributed to the antisymmetric stretching vibration of saturated hydrocarbon $\mathrm{CH}_{3}$, while the peak value around $2879 \mathrm{~cm}^{-1}$ corresponds to the symmetric stretching vibration of $\mathrm{CH}_{3}$. This indicates that the $\mathrm{C}-\mathrm{H}$ bond in Diesel particles mainly exists in the structure of $\mathrm{CH}_{2}$, while the $\mathrm{C}-\mathrm{H}$ bond in $\mathrm{Fe} 300$ mainly is mainly $\mathrm{CH}_{3}$. The peak to height ratio of $\mathrm{I}_{\mathrm{C}-\mathrm{H}} / \mathrm{I}_{\mathrm{C}=\mathrm{C}}$ in Diesel particles is 0.741 , and the peak to height ratio of $\mathrm{I}_{\mathrm{C}-\mathrm{H}} / \mathrm{I}_{\mathrm{C}=\mathrm{C}}$ in Fe300 is 1.359 .

The comparison shows that the concentration of $\mathrm{C}-\mathrm{H}$ in Fe300 particles is higher, while $\mathrm{C}-\mathrm{H}$ mainly exists on the edge of microcrystalline layer. Therefore, the increase of C-H bond concentration proves that the microcrystalline structure of Fe300 particles have a more disordered structure and a lower graphitization. The peak value of $\mathrm{Fe} 300$ particles around $1320 \mathrm{~cm}^{-1}$ is attributed to carboxylic acid $\mathrm{C}-\mathrm{OH}$, and the relative concentration of Fe300 particles is higher than that of Diesel. There is an obvious peak value of Fe300 particles at about $620 \mathrm{~cm}^{-1}$, which is mainly attributed to the oxide of iron.

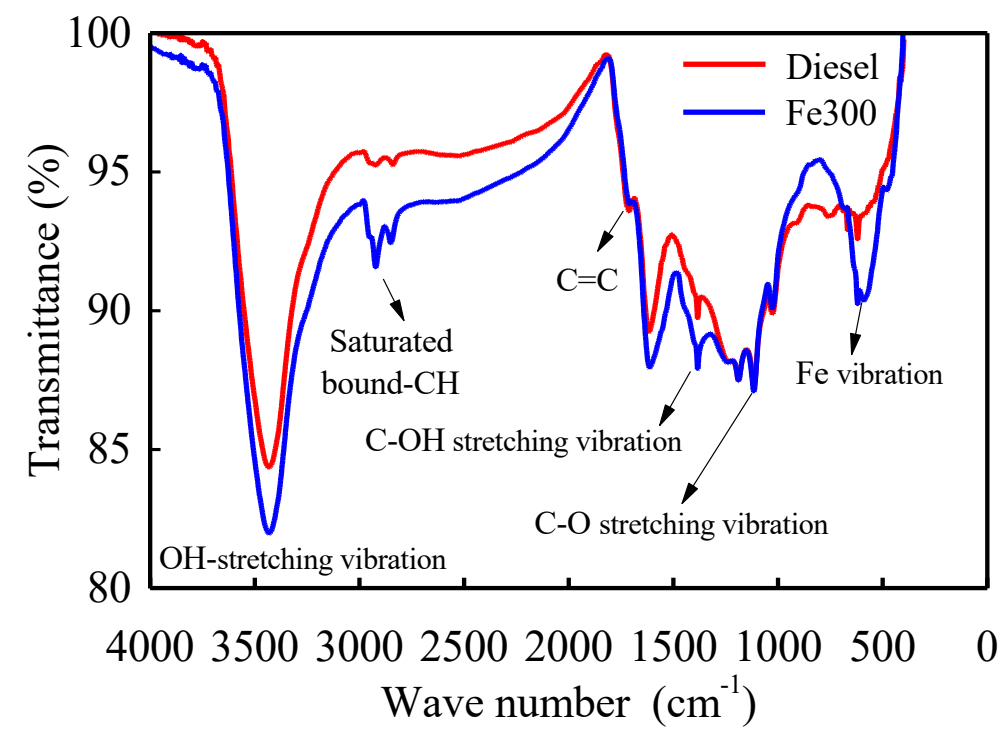

Fig. 7. FTIR spectrum of Diesel and Fe300 particles.

\subsection{Element analysis of soot particle}

XPS measurements are conducted to identify the element composition and functional group types of 
Diesel and Fe300 soot particles. Fig. 8 displays The XPS full-element spectra of Diesel and Fe300 soot particles and the Fe2p micro-scanning spectrogram of Fe300 soot particles. From the element counts from XPS wide sweep of Diesel and Fe300 soot particles in Fig. 8(a), it can be seen that the main elements of Diesel soot particles and Fe300 soot particles are $\mathrm{O}$ and $\mathrm{C}$ elements. Unlike Diesel soot particles, there is obvious peaks at $700 \mathrm{eV}$ in the XPS spectrum of Fe300 soot particles, which is mainly caused by the addition of Fe element, belonging to $\mathrm{Fe} 2 \mathrm{p}$. In addition, there are a small amount of $\mathrm{N}, \mathrm{S}$ and other trace metal elements. When only the $\mathrm{C}, \mathrm{O}$ and Fe elements contained in the soot particles are considered, the relative atomic percentages of $\mathrm{C}$ and $\mathrm{O}$ on the Diesel soot particles surface are $82.87 \%$ and $17.13 \%$, respectively. The relative atomic percentages of $\mathrm{C}, \mathrm{O}$ and $\mathrm{Fe}$ on $\mathrm{Fe} 300$ soot particles surface are $65.49 \%, 20.70 \%$ and $13.79 \%$, respectively. The comparison shows that the relative atomic content of $\mathrm{C}$ and $\mathrm{O}$ in $\mathrm{Fe} 300$ particles decreases by $17.38 \%$ and increases by $3.57 \%$.

Fig. 8(b) shows the original curve of Fe2p canning spectrogram of Fe300 soot particles and the fitting peaking curve. According to the analysis in the figure, four peaks are fitted in the Fe $2 \mathrm{p}$ microregion, and the types of groups and their corresponding mass fractions are shown in Table 3. The formation and oxidation of soot particles are closely related with Fe element. Fe element participates in the coagulation and agglomeration of carbon particles and restrains the growth of carbon particles, resulting in the decrease of the microcrystalline size of carbon particles and the increase of the layer spacing. $\mathrm{Fe}^{2+}, \mathrm{Fe}^{3+}, \mathrm{FeOOH} \mathrm{Fe}_{2} \mathrm{O}_{3}$ and $\mathrm{Fe}_{3} \mathrm{O}_{4}$ have special crystal structure, which can store and release oxygen atoms and provide oxygen-containing groups for particle oxidation. 

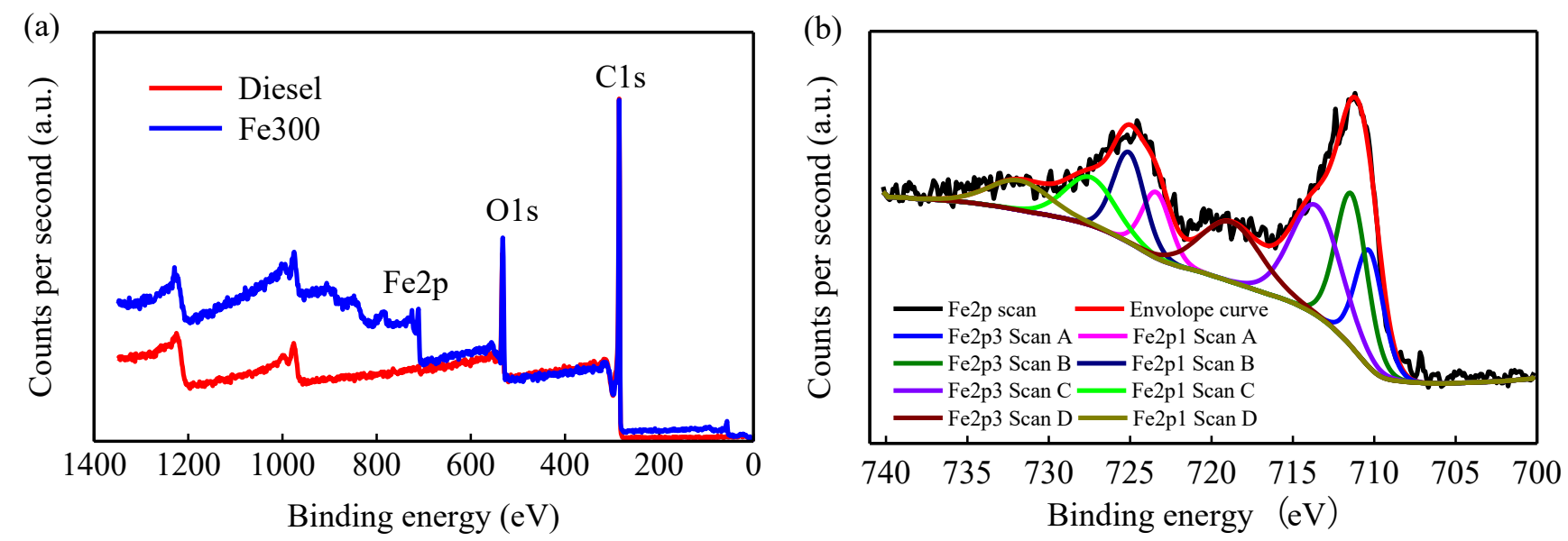

Fig. 8. XPS spectra: (a) Element counts from XPS wide sweep of Diesel and Fe300 soot particles;

(b) Fe2p spectra of Fe300 soot particles.

Table 3 Fe species ratio in Fe300 particle determined by XPS.

\begin{tabular}{ccccc}
\hline Binding energy $(\mathrm{eV})$ & 710.3 & 711.4 & 713.57 & 718.81 \\
\hline Assignment & $\mathrm{Fe}^{2+}$ or Fe$^{3+}$ & $\mathrm{FeOOH}$ & $\mathrm{Fe}_{2}\left(\mathrm{SO}_{4}\right)_{3}$ & $\mathrm{Fe}_{2} \mathrm{O}_{3}$ or $\mathrm{Fe}_{3} \mathrm{O}_{4}$ \\
Mass fraction & $19.10 \%$ & $27.82 \%$ & $32.08 \%$ & $20.99 \%$ \\
\hline
\end{tabular}

Fig. 9 presents the XPS spectra of Diesel and Fe300 soot particles in the C1s and O1s energy regions at rated power with $2600 \mathrm{r} / \mathrm{min}$. Compared with the C1s spectra of Diesel and Fe300 soot particles, it can be found that the C1s spectra is composed of four peaks, and the binding energy of peak position are $284.8 \mathrm{eV}$, $285.85 \mathrm{eV}, 287 \mathrm{eV}$ and $288.45 \mathrm{eV}$ respectively, which shows that the groups formed by $\mathrm{C}$ element are the same, respectively corresponding to $\mathrm{C}-\mathrm{C} / \mathrm{C}-\mathrm{H}, \mathrm{C}-\mathrm{O}, \mathrm{O}-\mathrm{H}$ and $\mathrm{C}=\mathrm{O}$, but the relative content is different. The mass fractions of the four groups in Diesel soot particles are $70.94 \%, 11.76 \%, 9.56 \%$ and $7.74 \%$, while those in Fe300 soot particles are 73.13\%, 11.94\%, 9.36\% and 5.57\%, respectively. By comparing the O1s spectra of Diesel and Fe300 soot particles, the O1s spectra of Diesel soot particles is composed of four peaks, with the binding energy of $530.62 \mathrm{eV}, 531.91 \mathrm{eV}, 532.98 \mathrm{eV}$ and $534.08 \mathrm{eV}$ respectively, corresponding to $\mathrm{Al}_{2} \mathrm{O}_{3}, \mathrm{OH}, \mathrm{C}-\mathrm{O}$ and $\mathrm{C}=\mathrm{O}$, among which the mass fraction of $\mathrm{OH}$ group is $32.11 \%$. However, the $\mathrm{O} 1 \mathrm{~s}$ spectra of Fe300 soot particles can be formed into four peaks. The binding energy of the peaks are $530.35 \mathrm{eV}$, $531.79 \mathrm{eV}, 532.8 \mathrm{eV}$ and $533.98 \mathrm{eV}$ respectively, corresponding to $\mathrm{Fe}_{3} \mathrm{O}_{4}$ or $\mathrm{FeOOH}, \mathrm{OH}, \mathrm{C}=\mathrm{O}$ and $\mathrm{C}-\mathrm{O}$, and the mass fraction of $\mathrm{OH}$ group is $32.54 \%$. Fe in soot is mainly bound to $\mathrm{O}$ and $\mathrm{OH}$ groups, accounting 
for $25.23 \%$ of the mass fraction.
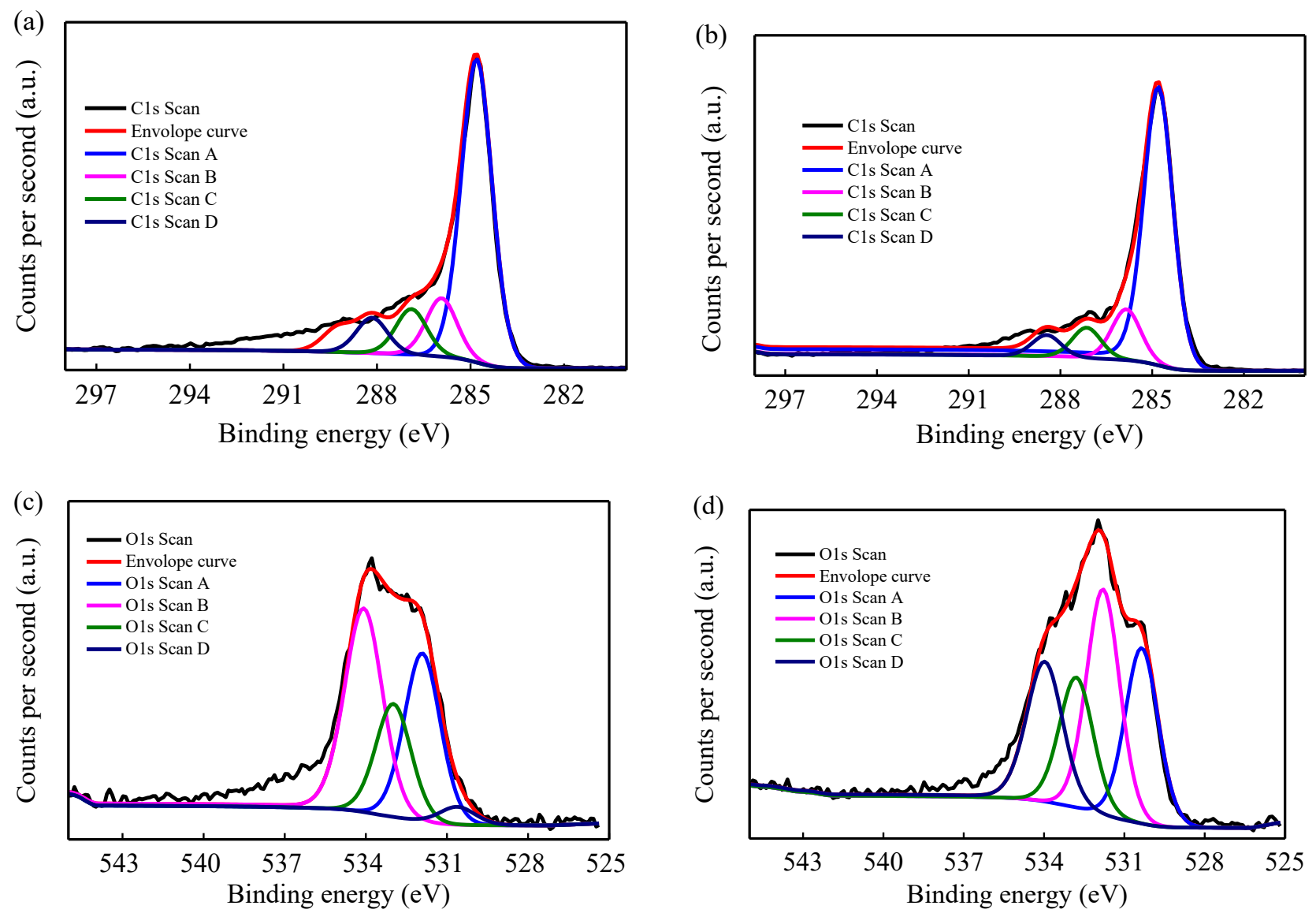

Fig. 9. XPS spectra: (a) C1s of Diesel particle;

(b) C1s of Fe300 particle; (c) O1s of Diesel particle; (d) O1s of Fe300 particle.

According to FTIR results, compared with Diesel soot particles, the content of OH with stronger oxidation in $\mathrm{Fe} 300$ soot particles is higher, while the proportion of $\mathrm{C}=\mathrm{O}$ is lower. On the one hand, this is due to the strong oxygen storage capacity of Fe lattice, which absorbs more oxygen atoms, leading to the increment in the number of oxygen-containing functional groups in particles [50], especially the increase in the number of $\mathrm{OH}$. On the other hand, Fe-FBC restrains the growth of carbon particles in the process of combustion, and increases the disorder of carbon particles, and the edge of carbon layer is more likely to bond with oxygen. Fe-FBC reduces the combustion temperature in the cylinder and the graphitization of the carbon layer of the particles, so the content of aliphatic $\mathrm{C}-\mathrm{H}$ bond which mainly exists on the carbon atom at the edge of the carbon microcrystalline increases. 


\subsection{Oxidation characteristics analysis}

The TG/DTG curves of Diesel and Fe300 particles are shown in Fig. 10. By comparison, the DTG curve of Diesel particles has two peaks, and the corresponding weight loss process includes volatilization and oxidation of the soluble organic fraction (SOF) and oxidation of soot. The temperature range of volatilization and oxidation of SOF is $100{ }^{\circ} \mathrm{C} \sim 210{ }^{\circ} \mathrm{C}$, the peak temperature of weight loss rate is $208^{\circ} \mathrm{C}$, the peak value of weight loss rate is $-0.00214 \% /{ }^{\circ} \mathrm{C}$, accounting for $12.1 \%$ of the mass of Diesel particles. During the oxidation process of soot, the temperature range is $300-620{ }^{\circ} \mathrm{C}$, the peak temperature of weight loss rate is $610{ }^{\circ} \mathrm{C}$, and the peak value of weight loss rate is $-0.00533 \% /{ }^{\circ} \mathrm{C}$, accounting for $81.5 \%$ of the mass of Diesel particles, and the residual ash content after oxidation reaction is $6.4 \%$. Compared with the Diesel, the DTG curve of Fe300 particles has three peaks. The first peak appears for the same reason as Diesel particles, which is the volatilization and oxidation of SOF. The peak temperature of weight loss rate is $215{ }^{\circ} \mathrm{C}$, and the peak value of weight loss rate is $-0.00283 \% /{ }^{\circ} \mathrm{C}$, accounting for $14.5 \%$ of the mass of $\mathrm{Fe} 300$ particles. The second peak is the volatilization and oxidation of semi-volatile organic compounds, which occurs in the temperature range of $300{ }^{\circ} \mathrm{C} \sim 400{ }^{\circ} \mathrm{C}$, accounting for $17.1 \%$ of the mass of Fe 300 particles. The third peak is the oxidation of soot, the peak temperature of weight loss rate is $479{ }^{\circ} \mathrm{C}$, and the peak value of weight loss rate is $-0.00368 \% /{ }^{\circ} \mathrm{C}$, accounting for $49.9 \%$ of the mass of $\mathrm{Fe} 300$ particles. The proportion of residual ash after oxidation reaction is $18.5 \%$.
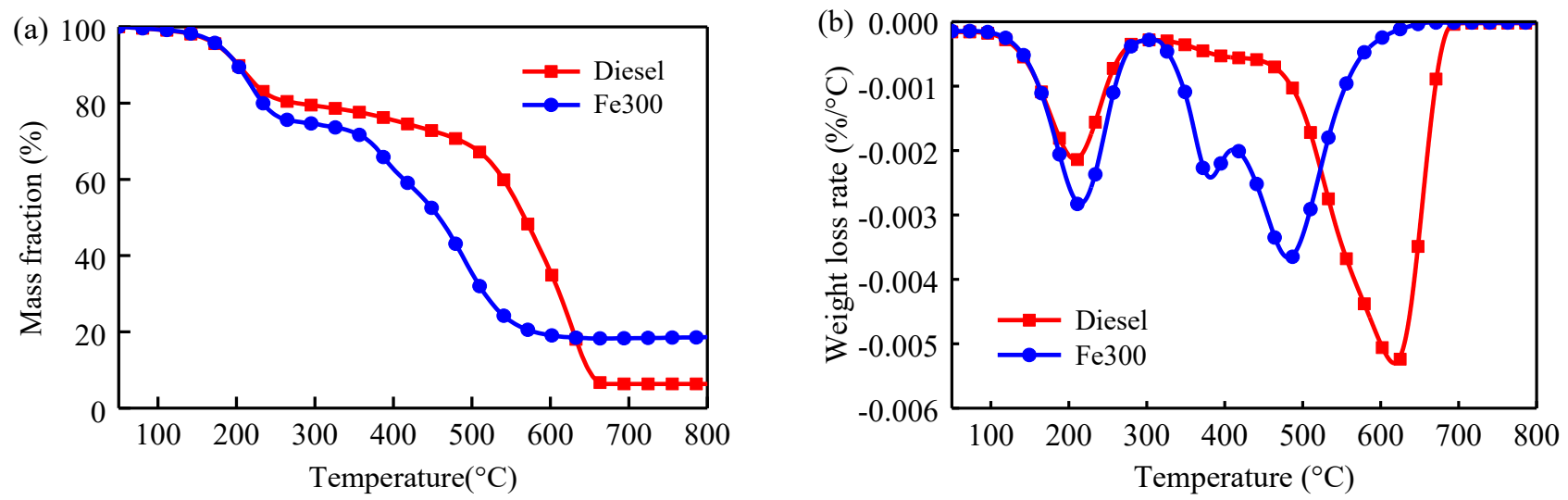

Fig. 10. TG (a) and DTG (b) curves of Diesel and Fe300 particles. 
Reaction conditions: reactor-TGA, feed gas - a mixture of nitrogen and oxygen according to $4: 1$, heating rate $-10^{\circ} \mathrm{C} / \mathrm{min}$.

Compared with Diesel particles, the content of SOF in Fe300 particles increases, the content of soot decreases, the content of ash increases, and the peak temperature of weight loss rate shifts to the low temperature regions. The reason for the second oxidation peak in Fe300 particles may be that Fe oxides act as the catalytic center to induce a small amount of substance (semi-volatile organic components) between SOF and soot to oxidize before soot. During the oxidation process of soot, the ignition temperature of Fe 300 particles decreases by $65^{\circ} \mathrm{C}$ and the peak temperature of weight loss rate decreases by $131{ }^{\circ} \mathrm{C}$, indicating that the addition of Fe-FBC improves the oxidation activity of soot particles. In order to quantitatively analyze the influence of Fe-FBC on the oxidation activity of soot particles, Coats-Redfern integral method is used to analyze the activation energy of Diesel and Fe300 particles in the temperature range of $400 \sim 700^{\circ} \mathrm{C}$. It can provide a reference for the temperature required to oxidize soot particles during DPF regeneration process. The linear equation of the fitting line and the parameters are shown in Table 4.

Table 4 Calculated kinetic parameters of soot particle samples.

\begin{tabular}{llll}
\hline Fuels & Fitting equation & Regression coefficient $/ \mathrm{R}^{2}$ & Activation energy $(\mathrm{kJ} / \mathrm{mol})$ \\
\hline Diesel & $\mathrm{y}=-6734.766 \mathrm{x}-5.2829$ & 0.9984 & 55.982 \\
Fe300 & $\mathrm{y}=-2915.473 \mathrm{x}-9.2263$ & 0.9981 & 24.235 \\
\hline
\end{tabular}

It can be seen from the analysis in Table 4 that compared with Diesel particles, the pyrolysis activation energy of Fe300 particles is reduced by $56.7 \%$, which is because Fe can suppress the coalescence and agglomeration of carbon particles, resulting in the decrease of particle size and the increase of specific surface area. After combustion, the combination of catalyst and particles is closer and the dispersion is more evenly. The active sites provided by Fe are increased, and the catalytic effect is better. In addition, the addition of Fe element makes the particles have more Fe lattice, and the Fe lattice has a special spatial structure. There is a certain oxygen vacancy that can be incorporated into the oxygen atom, and at the same time, it increases the curvature of the micro carbon layer of the particles [51], making the particles more 
easily react with oxygen, thus improving the oxidation ability of the active center to the particles, and further reducing the activation energy of the reaction. Therefore, the pyrolysis rate of Fe300 particles increases, the temperature range of oxidation reaction tends to the low temperature regions, and the reaction duration is significantly shortened $[52,53]$.

Previous studies show that fuel properties such as cetane number, element fraction, aromatic hydrocarbon fraction, heat value, etc. play important roles in the physical process of air-fuel mixture and chemical process of combustion in the cylinder of engine [54]. Especially, the improvement of diesel quality with the decrease of sulfur content leads to the continuous reduction of diesel particle emission. Moreover, the particle number and particulate matter emissions decrease significantly with the oxygenated fuel blends [55]. The addition of Fe-FBC into diesel fuel has present some potential advantages, for instance, it could improve the combustion process, and decrease the NOx, smoke and particle mass emissions and the particle activation energy. While the addition of Fe or other metal elements into diesel fuel may lead to the increase of particle number emission or residual ash. However, the combined application of metal-based FBC and DPF methods can not only control the amount of particle emission, but also benefit the regeneration performance of DPF $[11,32]$.

\section{Conclusions}

In the current research, the effects of iron-based fuel borne catalyst (Fe-FBC) addition on the fuel economy, NOx and particulate matter emissions of diesel engine were studied, and the physicochemical characteristics of Diesel and Fe-FBC particles were compared, such as particle size distribution, microstructure, oxidation activity, etc. The main conclusions are as follows:

(1) The brake specific fuel consumption of diesel engine decreases with the addition of Fe-FBC into diesel fuel, among which the reduction extent of Fe300 and Fe400 are more obvious. With the increase of Fe-FBC ratio, the NOx and smoke emissions of engine are significantly decreased. 
(2) After burning Fe300 fuel, the total mass concentration of diesel exhaust particles decreases, and the overall particle size shifts from coarse mode to accumulation mode. However, the number concentration distribution of exhaust particles shifts to the nuclear mode, and the total number concentration increases.

(3) Compared with Diesel particles, the carbon particles of Fe300 particles have larger layer spacing and microcrystalline curvature, smaller microcrystalline size, weaker graphitization, higher disorder degree of carbon particle structure and higher oxidation activity.

(4) The contents of $\mathrm{OH}$ and aliphatic $\mathrm{C}-\mathrm{H}$ in Fe300 particle sample are higher than those in Diesel particle sample. Compared with Diesel particles, the $\mathrm{C}$ atoms content of Fe300 particles decreases by $17.38 \%$, and the $\mathrm{O}$ atoms content increases by $3.57 \%$.

(5) The addition of Fe-FBC in diesel fuel results in semi-volatile organic compounds in the particles. Compared with Diesel particles, the ignition temperature of $\mathrm{Fe} 300$ particles decreases by $65{ }^{\circ} \mathrm{C}$, the peak temperature of weight loss rate decreases by $131{ }^{\circ} \mathrm{C}$, and the activation energy of pyrolysis decreases by $56.7 \%$, which indicates the oxidation activity of Fe300 particles increases.

\section{Acknowledgement}

This work was supported by the National Natural Science Foundation of China (No. 51806086) and State Key Laboratory of Engines, Tianjin University (K2019-08).

\section{References}

[1] D. Han, A.M. Ickes, D.N. Assains, Z. Huang, S.V. Bohac. Attainment and load extension of high efficiency premixed low temperature combustion with dieseline in a compression ignition engine. Energy Fuels 2010; 24: 3517-25.

[2] D. Han, A. Ickes, S. Bohac, Z. Huang, D. Assanis. Premixed low-temperature combustion of blends of diesel and gasoline in a high speed compression ignition engine. Proc Combust Inst 2011; 33: 3039-46. 
[3] Z. Zheng, L. Yue, H. Liu, Y. Zhu, X. Zhong, M. Yao. Effect of two-stage injection on combustion and emissions under high EGR rate on a diesel engine by fueling blends of diesel/gasoline, diesel/n-butanol, diesel/gasoline/n-butanol and pure diesel. Energy Convers Manage 2015; 90: 1-11.

[4] H. Liu, S. Li, Z. Zheng, J. Xu, M. Yao. Effects of n-butanol, 2-butanol, and methyl octynoate addition to diesel fuel on combustion and emissions over a wide range of exhaust gas recirculation (EGR) rates. Appl Energy 2013; 112: 246-56.

[5] P. Rounce, A. Tsolakis, A.P.E. York. Speciation of particulate matter and hydrocarbon emissions from biodiesel combustion and its reduction by aftertreatment. Fuel 2012; 96: 90-9.

[6] Z.W. Meng, J.S. Li, J. Fang, J. Tan, Y. Qin, Y. Jiang, Z.H. Qin, W.L. Bai, K. Liang. Experimental study on regeneration performance and particle emission characteristics of DPF with different inlet transition sections lengths. Fuel 2020; 262: 116487.

[7] Z.W. Meng, C. Chen, J.S. Li, J. Fang, J. Tan, Y. Qin, Y. Jiang, Z.H. Qin, W.L. Bai, K. Liang. Particle emission characteristics of DPF regeneration from DPF regeneration bench and diesel engine bench measurements. Fuel 2020; 262: 116589 .

[8] H.L. Zhang, O. Pereira, G. Legros, E.E. Iojoiu, M.E. Galvez, Y.Q. Chen, P.D. Costa. Structure-reactivity study of model and Biodiesel soot in model DPF regeneration conditions. Fuel 2019; 239: 373-86.

[9] V. Macián, J.R. Serrano, P. Piqueras, E.J. Sanchis. Internal pore diffusion and adsorption impact on the soot oxidation in wall-flow particulate filters. Energy 2019; 179: 407-21.

[10] V. Palma, P. Ciambelli, E. Meloni, A. Sin. Catalytic DPF microwave assisted active regeneration. Fuel 2015; 140: $50-61$.

[11] Z. Stępień, L. Ziemiański, G. Żak, M. Wojtasik, Ł. Jęczmionek, Z. Burnus. The evaluation of fuel borne catalyst (FBC's) for DPF regeneration. Fuel 2015; 161: 278-86.

[12] V. Palma, P. Ciambelli, E. Meloni, A. Sin. Optimal $\mathrm{CuFe}_{2} \mathrm{O}_{4}$ load for MW susceptible catalysed DPF. Chem Eng Trans 2013; 35: 727-32. 
[13] V. Palma, P. Ciambelli, E. Meloni, A. Sin. Study of the catalyst load for a microwave susceptible catalytic DPF. Catal Today 2013; 216: 185-93.

[14] M.A. Lenin, M.R. Swaminathan, G. Kumaresan. Performance and emission characteristics of a DI diesel engine with a nanofuel additive. Fuel 2013; 109: 362-5.

[15] S. Gumus, H. Ozcan, M. Ozbey, B. Topaloglu. Aluminum oxide and copper oxide nanodiesel fuel properties and usage in a compression ignition engine. Fuel 2016; 163: 80-7.

[16] G. Najafi. Diesel engine combustion characteristics using nano-particles in biodiesel-diesel blends. Fuel 2018; 212: $668-78$.

[17] V.A.M. Selvan, R.B. Anand, M. Udayakumar. Effect of Cerium Oxide Nanoparticles and Carbon Nanotubes as fuel-borne additives in Diesterol blends on the performance, combustion and emission characteristics of a variable compression ratio engine. Fuel 2014; 130: 160-7.

[18] M. Celik, H.S. Yucesu, M. Guru. Investigation of the effects of organic based manganese addition to biodiesel on combustion and exhaust emissions. Fuel Process Technol 2016; 152: 83-92.

[19] I. Javed, S.W. Baek, K. Waheed. Autoignition and combustion characteristics of heptane droplets with the addition of aluminium nanoparticles at elevated temperatures. Combust Flame 2015; 162: 191-206.

[20] A.C. Sajeevan, V.J.F. Sajith. Synthesis of stable cerium zirconium oxide nanoparticle-Diesel suspension and investigation of its effects on diesel properties and smoke. Fuel 2016; 183: 155-63.

[21] R. Ran, D. Weng, X. Wu, J. Fan, L. Wang, X. Wu. Structure and oxygen storage capacity of Pr-doped $\mathrm{Ce}_{0.26} \mathrm{Zr}_{0.74} \mathrm{O}_{2}$ mixed oxides. J Rare Earth 2011; 29: 1053-9.

[22] A. Keskin, M. Gürü, D. Altıparmak. Influence of metallic based fuel additives on performance and exhaust emissions of diesel engine. Energy Convers Manage 2011; 52(1): 60-5.

[23] M.S. Gross, M.A. Ulla, C.A. Querini. Diesel particulate matter combustion with $\mathrm{CeO}_{2}$ as catalyst. Part I: System characterization and reaction mechanism. J Mol Catal A: Chem 2012; 352: 86-94. 
[24] K. Krishna, A. Bueno-López, M. Makkee, J.A. Moulijn. Potential rare earth modified $\mathrm{CeO}_{2}$ catalysts for soot oxidation: I. Characterisation and catalytic activity with $\mathrm{O}_{2}$. Appl Catal B: Environ 2007; 75(3-4): 189-200.

[25] H.H. Yang, W.J. Lee, H.H. Mi, C.H. Wong, C.B. Chen. PAH emissions influenced by Mn-based additive and turbocharging from a heavy-duty diesel engine. Environ Int 1998; 24(4): 389-403.

[26] A. Raj, E. Croiset, Wen J.Z. Numerical analysis of effects of iron pentacarbonyl as fuel additive for reducing NO and soot precursors from methane/air diffusion flame. Fuel 2018; 216: 768-80.

[27] M. Mehregan, M. Moghiman. Effect of aluminum nanoparticles on combustion characteristics and pollutants emission of liquid fuels - A numerical study. Fuel 2014; 119: 57-61.

[28] J. Zhang, C.M. Megaridis. Iron/soot interaction in a laminar ethylene nonpremixed flame. Symp (Int) Combust 1994; 25: 593-600.

[29] D.G. Nash, N.B. Swanson, W.T. Preston, T.L.B. Yelverton, W.L. Roberts, J.O.L. Wendt, W.P. Linak. Environmental implications of iron fuel borne catalysts and their effects on diesel particulate formation and composition. J Aerosol Sci 2013; 58: 50-61.

[30] Y. Ma, M. Zhu, D. Zhang. The effect of a homogeneous combustion catalyst on exhaust emissions from a single cylinder diesel engine. Appl Energy 2013; 102: 556-62.

[31] Z.H. Zhang, R. Balasubramanian. Influence of an iron-based fuel-borne catalyst on physicochemical and toxicological characteristics of particulate emissions from a diesel engine. Appl Energy 2015; 146: 270-8.

[32] H. Zhao, Y. Ge, T. Zhang, J. Zhang, J. Tan, H. Zhang. Unregulated emissions from diesel engine with particulate filter using Fe-based fuel borne catalyst. J Environ Sci 2014; 26(10): 2027-33.

[33] C. Hu, W. Li, Q. Lin, X. Cheng, Q. Huang, H. Zhang, Z. Wang. Effects of ferrocene on flame temperature, formation of soot particles and growth of polycyclic aromatic hydrocarbons. J Energy Inst 2017; 90(6): 893-901.

[34] M. Alfè, B. Apicella, R. Barbella, J.N. Rouzaud, A. Tregrossi, A. Ciajolo. Structure-property relationship in nanostructures of young and mature soot in premixed flames. Proc Combust Inst 2009; 32: 697-704. 
[35] L. Wang, C. Song, J. Song, G. Lv, H. Pang, W. Zhang. Aliphatic C-H and oxygenated surface functional groups of diesel in-cylinder soot: characterizations and impact on soot oxidation behavior. Proc. Combust. Inst 2013; 34: 3099-106.

[36] J. Liu, J. Yang, P. Sun, W. Gao, C. Yang, J. Fang. Compound combustion and pollutant emissions characteristics of a common-rail engine with ethanol homogeneous charge and polyoxymethylene dimethyl ethers injection. Appl Energy 2019; 239: 1154-62.

[37] J. Liu, J. Yang, P. Sun, Q. Ji, J. Meng, P. Wang. Experimental investigation of in-cylinder soot distribution and exhaust particle oxidation characteristics of a diesel engine with nano- $\mathrm{CeO}_{2}$ catalytic fuel. Energy 2018; 161: 17-27.

[38] R.L. Vander Wal, A.J. Tomasek, M.I. Pamphlet, C.D. Taylor, W.K. Thompson. Analysis of HRTEM images for carbon nanostructure quantification. J. Nanopart Res 2004; 6: 555-68.

[39] J.P.A. Neeft, T.X. Nijhuls, E. Smakman, M. Makkee, J. Moulijn. Kinetics of the oxidation of diesel soot. Fuel 1997; 76: 1129-36

[40] X. Wang, S. Li, A. Adeosun, Y. Li, Milan Vujanović, Houzhang Tan, N. Duić. Effect of potassium-doping and oxygen concentration on soot oxidation in $\mathrm{O}_{2} / \mathrm{CO}_{2}$ atmosphere: a kinetics study by thermogravimetric analysis. Energy Convers Manag 2017; 149: 686-97.

[41] J. Liu, P. Sun, H. Huang, J. Meng, X. Yao. Experimental investigation on performance, combustion and emission characteristics of a common-rail diesel engine fueled with polyoxymethylene dimethyl ethers-diesel blends. Appl Energy 2017; 202: 527-36.

[42] A. Prabu, R.B. Anand. Emission control strategy by adding alumina and cerium oxide nano particle in biodiesel. J Energy Inst 2016; 89: 366-32.

[43] D. Reichert, H. Bockhorn, S. Kureti. Study of the reaction of $\mathrm{NOx}$ and soot on $\mathrm{Fe}_{2} \mathrm{O}_{3}$ catalyst in excess of $\mathrm{O}_{2}$. Appl Catal B 2008; 80: 248-59.

[44] S. Wagloehner, S. Kureti. Study on the mechanism of the oxidation of soot on $\mathrm{Fe}_{2} \mathrm{O}_{3}$ catalyst. Appl Catal B 2012; 125 : 
$158-65$.

[45] G. Mul, F. Kapteijn, C. Doornkamp, J.A. Moulijn. Transition metal oxide catalyzed carbon black oxidation: a study with ${ }^{18} \mathrm{O}_{2}$. J. Catal 1998; 179: 258-266.

[46] A. Miller, G. Ahlstrand, D. Kittelson, M. Zachariah. The fate of metal (Fe) during diesel combustion: Morphology, chemistry, and formation pathways of nanoparticles. Combust Flame 2007; 149(1-2): 129-43.

[47] W. Gao, J. Liu, P. Sun, C. Yang, J. Fang. Gaseous emissions and particle microstructure characteristics of PODE/Diesel blend fuel. Int J Automot Techn 2019; 20(3): 607-17.

[48] H. Zhang, S. Li, Y. Jiao, E. Emil iojoiu, P.D. Costa, M.E. Galvez, Y. Chen. Structure, surface and reactivity of activated carbon: From model soot to Bio Diesel soot. Fuel 2019; 257: 116038.

[49] P. Faber, F. Drewnick, R. Bierl, S. Borrmann. Complementary online aerosol mass spectrometry and offline FT-IR spectroscopy measurements: Prospects and challenges for the analysis of anthropogenic aerosol particle emissions. Atmos Environ 2017; 166: 92-8.

[50] B.R. Stanmore, J.F. Brilhac, P. Gilot. The oxidation of soot: a review of experiments, mechanisms and models. Carbon 2001; 39: 2247-68.

[51] I. Morjan, I. Voicu, R. Alexandrescu, I. Pasuk, I. Sandu, F. Dumitrache, I. Soare, TC. Fleaca, M. Ploscaru, V. Ciupina, H. Daniels, A. Westwood, B. Rand. Gas composition in laser pyrolysis of hydrocarbon-based mixtures: Influence on soot morphology. Carbon 2004; 42(7): 1269-73.

[52] D.S. Su, R.E. Jentoft, J.-O. Müller, D. Rothe, E. Jacob, C.D. Simpson, Z. Tomovic, K. Müllen, A. Messerer, U. Pöschl, R. Niessner, R. Schlögl. Microstructure and oxidation behaviour of Euro IV diesel engine soot: a comparative study with synthetic model soot substances. Catal Today 2004; 90(1-2): 127-32.

[53] J.O. Müller, D.S. Su, R.E. Jentoft, J. Kröhnert, F.C. Jentoft, R. Schlögl. Morphology-controlled reactivity of carbonaceous materials towards oxidation. Catal Today 2005; 102-103: 259-65.

[54] H. Liu, X. Wang, D. Zhang, F. Dong, X. Liu, Y. Yang, H. Huang, Y. Wang, Q. Wang, Z. Zheng. Investigation on 
Blending Effects of Gasoline Fuel with N-Butanol, DMF, and Ethanol on the Fuel Consumption and Harmful Emissions in a GDI Vehicle. Energies 2019; 12: 1845.

[55] H. Liu, J. Ma, F. Dong, Y. Yang, X. Liu, G. Ma, Z. Zheng, M. Yao. Experimental investigation of the effects of diesel fuel properties on combustion and emissions on a multi-cylinder heavy-duty diesel engine. Energy Convers Manage 2018; 171: 1787-800. 